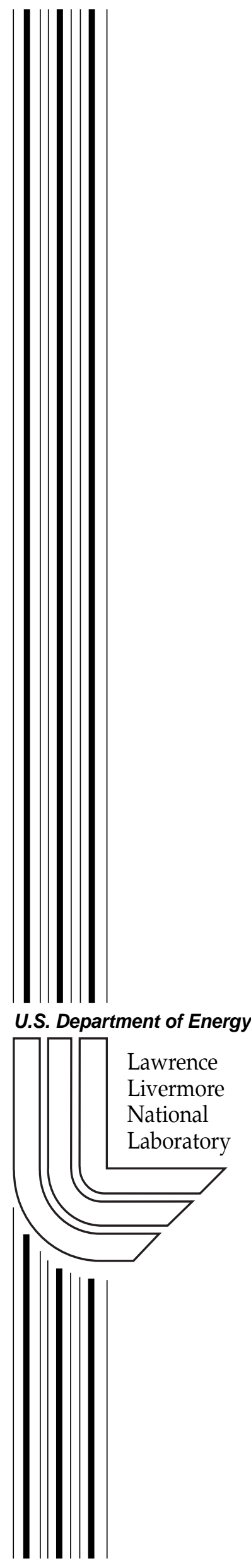

Preprint

UCRL-JC-141175

\title{
Matrix Formulation of a Universal Microbial Transcript Profiling System
}

J. P. Fitch, J. Ng, B. A. Sokhansanj

This article was submitted to International Conference of Acoustics, Speech, and Signal Processing, Salt Lake City, UT, May 7-11, 2000

\section{November 1, 2000}




\section{DISCLAIMER}

This document was prepared as an account of work sponsored by an agency of the United States Government. Neither the United States Government nor the University of California nor any of their employees, makes any warranty, express or implied, or assumes any legal liability or responsibility for the accuracy, completeness, or usefulness of any information, apparatus, product, or process disclosed, or represents that its use would not infringe privately owned rights. Reference herein to any specific commercial product, process, or service by trade name, trademark, manufacturer, or otherwise, does not necessarily constitute or imply its endorsement, recommendation, or favoring by the United States Government or the University of California. The views and opinions of authors expressed herein do not necessarily state or reflect those of the United States Government or the University of California, and shall not be used for advertising or product endorsement purposes.

This is a preprint of a paper intended for publication in a journal or proceedings. Since changes may be made before publication, this preprint is made available with the understanding that it will not be cited or reproduced without the permission of the author.

This work was performed under the auspices of the United States Department of Energy by the University of California, Lawrence Livermore National Laboratory under contract No. W-7405-Eng-48.

This report has been reproduced directly from the best available copy.

Available electronically at http://www.doc.gov/bridge

Available for a processing fee to U.S. Department of Energy

And its contractors in paper from

U.S. Department of Energy

Office of Scientific and Technical Information

P.O. Box 62

Oak Ridge, TN 37831-0062

Telephone: (865) 576-8401

Facsimile: (865) 576-5728

E-mail: reports@adonis.osti.gov

Available for the sale to the public from

U.S. Department of Commerce

National Technical Information Service

5285 Port Royal Road

Springfield, VA 22161

Telephone: (800) 553-6847

Facsimile: (703) 605-6900

E-mail: orders@ntis.fedworld.gov

Online ordering: http://www.ntis.gov/ordering.htm

OR

Lawrence Livermore National Laboratory

Technical Information Department's Digital Library

http://www.llnl.gov/tid/Library.html 


\title{
MATRIX FORMULATION OF A UNIVERSAL MICROBIAL TRANSCRIPT PROFILING SYSTEM
}

\author{
J. Patrick Fitch, Jefferson Ng, and Bahrad A. Sokhansanj \\ Biology \& Biotechnology Research Program \\ Lawrence Livermore National Laboratory; University of California \\ L-452, 7000 East Avenue; Livermore, CA 94550
}

\begin{abstract}
DNA chips and microarrays are used to profile gene transcription. Unfortunately, the initial fabrication cost for a chip and the reagent costs to amplify thousands of open reading frames for a microarray are over $\$ 100 \mathrm{~K}$ for a typical 4 Mbase bacterial genome. To avoid these expensive steps, a matrix formulation of a universal hybrid chip-microarray approach to transcript profiling is demonstrated for synthetic data. Initial considerations for application to the 4.3 Mbase bacterium Yersinia pestis are also presented. This approach can be applied to arbitrary bacteria by recalculating a matrix and pseudoinverse. This approach avoids the large upfront expenses associated with DNA chips and microarrays.
\end{abstract}

\section{INTRODUCTION}

The adenine (A), cytosine (C), guanine (G), and thymine ( $\mathrm{T}$ ) nitrogenous bases of DNA preferentially bind A-to-T and G-to-C. The complementary base pairing property can be used as a powerful detection method by the hybridizing (binding) of a reference strand of DNA to a test strand. DNA sequencing, transcript profiling, and clinical diagnostics are a few of the applications that exploit DNA hybridization. This paper focuses on transcript profiling applications to detect the level of mRNA (gene expression). The hybridization approaches are derived from DNA chips [1],

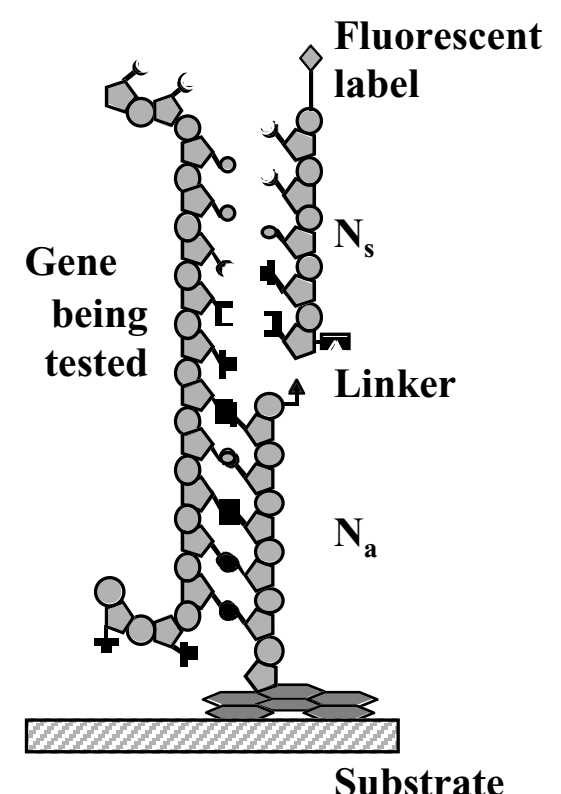

Fig. 1. Description of hybridization experiment for transcript profiling.

DNA microarrays [2], and sequencing by hybridization methods [3].

The matrix approach that we propose is based on a generalized experiment described graphically in Fig. 1. Detection of a test strand of DNA is accomplished by hybridization with a complementary reference strand of length $\mathrm{N}=\mathrm{N}_{\mathrm{a}}+\mathrm{N}_{\mathrm{s}}$. The $\mathrm{N}-\mathrm{mer}$ is composed of an array of $\mathrm{N}_{\mathrm{a}}$-mers attached to a glass substrate in a manner similar to microarrays. The additional $\mathrm{N}_{\mathrm{s}}$ bases for the detection are introduced in solution. Using extension enzymes or special linker chemistries, the discrimination power after hybridization is the same as with a whole $\mathrm{N}$-mer. Even when multiple $\mathrm{N}_{\mathrm{s}}$-mers hybridize 


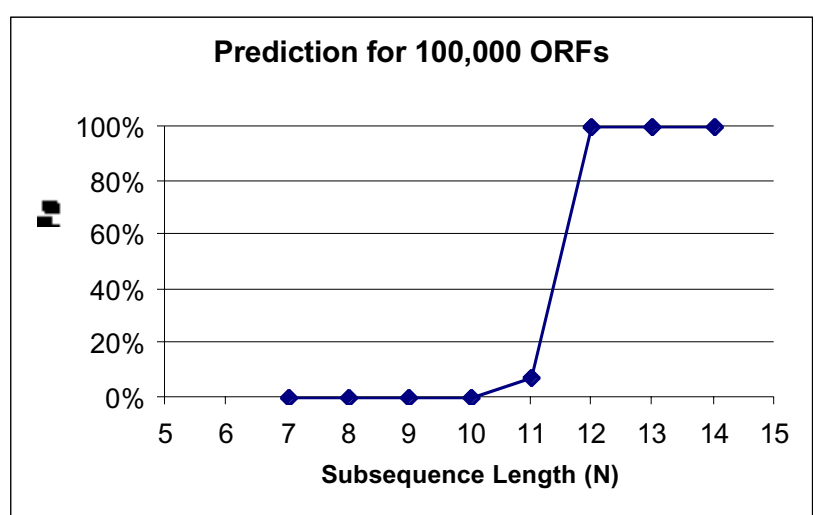

Fig. 2. Model prediction that 12 bases are needed to discriminate 100,000 genes (ORFs).

to the same spot, we want to identify the source genes. One solution is to place the competing $\mathrm{N}_{\mathrm{s}}$-mers into separate pools or experiments.

Our goal is to monitor message RNA level of most genes (over 90\%) in a prokaryotic organism (bacterium) without custom microarrays. Nothing in the described method limits the approach to prokaryotes. The hybridization, however, is currently restricted in oligonucleotide length to about 10 bases. As the length increases from 10-mers to 12-mers and longer (see Fig. 2), eukaryotic profiling including human gene profiling will be possible with the same technique [4].

\section{MATRIX FORMULATION}

A matrix formulation of the experiment is $\mathbf{M}=$ P D G, where

$\mathbf{G}=$ gene expression vector to be estimated ( $\mathrm{g} \mathrm{x}$ 1 column vector) representing the level of activity for $\mathrm{g}$ genes.

$\mathbf{D}=$ DNA matrix $\left(4^{\mathrm{N}} \mathrm{x}\right.$ g) that maps individual genes into constitutive N-mers. Let $\mathbf{D}(\mathrm{i}, \mathrm{j})$ be the value of $\mathbf{D}$ at position (i,j) where $(i, j)$ run $(1,1)$ to $\left(4^{\mathrm{N}}, \mathrm{g}\right) . \mathbf{D}(\mathrm{i}, \mathrm{j})$ is defined as the number of times that the $i$ th $\mathrm{N}$-mer occurs in gene $\mathrm{j}$.

$\mathrm{N}=\mathrm{N}_{\mathrm{a}}+\mathrm{N}_{\mathrm{s}}$ is the number of bases in the DNA reference strand.

$\mathrm{N}_{\mathrm{a}}=$ number of bases in the oligos attached to the substrate.

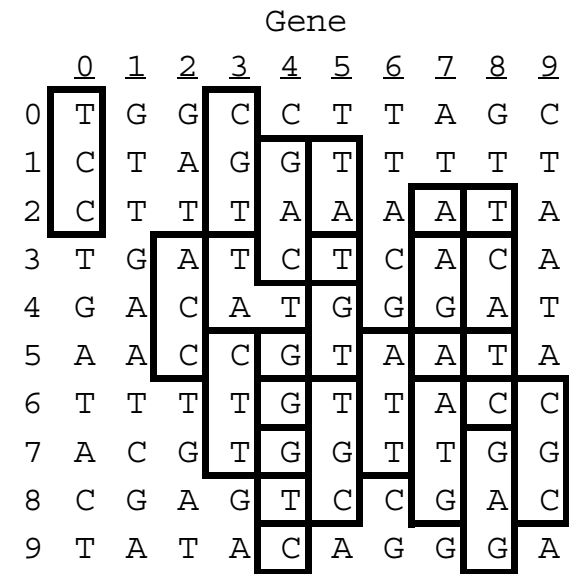

Fig. 3. Ten genes of length 10 are used as a synthetic genome for demonstrating the technique. Unique 3-mers indicating the discrimination power of the detection are highlighted. Note that there is no 3-mer unique to gene \#1.
$\mathrm{N}_{\mathrm{s}}=$ number of bases in the oligo extension introduced in solution during hybridization.
$\mathbf{P}=$ pooling matrix $\left(\mathrm{p} 4^{\mathrm{Na}} \times 4^{\mathrm{N}}\right)$ where $\mathrm{p}$ is the number of experimental pools.
$\mathbf{M}=$ measurement vector $\left(\mathrm{p} 4^{\mathrm{Na}} \times 1\right.$ column vector) representing the outcome of an experiment.

We have assumed that all possible $\mathrm{N}_{\mathrm{a}}$-mers are attached to the substrate. The matrix formulation is more general than this and any set of oligos (even of varying lengths) could have been used. However, we anticipate using the HyChip ${ }^{\mathrm{TM}}$ by HySeq for our transcript profiling and it uses all possible 5-mers at this time [5].

With the experiment constructed as a matrix multiply, the same approach as in the classic $\mathbf{A x}=\mathbf{b}$ matrix formulation can be used. Recall that if $\mathbf{A} \mathbf{A}^{\mathrm{T}}$ is invertible, then the optimal least squares solution or pseudoinverse is

$$
\mathbf{x}_{\mathbf{L S}}=\mathbf{A}^{\mathrm{T}}\left(\mathbf{A} \mathbf{A}^{\mathrm{T}}\right)^{-1} \mathbf{b} \text {. }
$$

\section{EXAMPLE}

To demonstrate the matrix approach, consider an artificial genome with 10 genes of 10 randomly assigned bases. In Fig. 3, we show the genes as 


\begin{tabular}{lllllllllll} 
& \multicolumn{10}{c}{ Gene } \\
& $\underline{\mathbf{0}}$ & $\underline{\mathbf{1}}$ & $\underline{\mathbf{2}}$ & $\underline{\mathbf{3}}$ & $\underline{\mathbf{4}}$ & $\underline{\mathbf{5}}$ & $\underline{\mathbf{6}}$ & $\underline{\mathbf{7}}$ & $\underline{\mathbf{8}}$ & $\underline{\mathbf{9}}$ \\
AAA & 0 & 0 & 0 & 0 & 0 & 0 & 0 & 0 & 0 & 0 \\
$\mathrm{AAC}$ & 0 & 0 & 0 & 0 & 0 & 0 & 0 & 0 & 0 & 0 \\
$\mathrm{AAG}$ & 0 & 0 & 0 & 0 & 0 & 0 & 0 & 1 & 0 & 0 \\
$\mathrm{AAT}$ & 0 & 1 & 0 & 0 & 0 & 0 & 0 & 1 & 0 & 1 \\
$\mathrm{ACA}$ & 0 & 0 & 0 & 0 & 0 & 0 & 0 & 0 & 0 & 0 \\
ACC & 0 & 0 & 1 & 0 & 0 & 0 & 0 & 0 & 0 & 0 \\
ACG & 0 & 0 & 0 & 0 & 0 & 0 & 1 & 0 & 0 & 1 \\
ACT & 1 & 0 & 0 & 1 & 1 & 0 & 0 & 0 & 0 & 0 \\
AGA & 0 & 0 & 0 & 0 & 0 & 0 & 0 & 1 & 0 & 0 \\
AGC & 0 & 0 & 0 & 0 & 0 & 0 & 0 & 0 & 0 & 0
\end{tabular}

Fig. 4. The first 10 rows of the 64 row by 10 column D matrix. Rows with a single nonzero element are unique identifiers of a gene. For instance, $\mathrm{AAG}$ is 0 except for the 1 in the gene 7 column. Compare these entries with the highlighted 3-mers in Fig. 2.

well as highlighting the unique 3-mers i.e., a 3 -mer that appears in only one gene.

For this example, we use a 3-mer reference strand $(\mathrm{N}=3)$ comprised of a single base attached to a substrate $\left(\mathrm{N}_{\mathrm{a}}=1\right)$ and a 2 -mer in solution $\left(\mathrm{N}_{\mathrm{s}}=2\right)$. There are four spots on the slide $(\mathrm{A}, \mathrm{C}$, $\mathrm{G}$, and $\mathrm{T}$ ). A few of the rows of the $\mathbf{D}$ matrix generated from the genes in Fig. 3 are shown in Fig. 4. The first $\mathrm{N}_{\mathrm{a}}$ bases in the index column (the first $\mathrm{A}$ for the rows in Fig. 4) correspond to the attached $\mathrm{N}_{\mathrm{a}}$-mers so that the pooling and measurement matrices are easier to interpret. Rows that contain a single non-zero element represent 3-mers that uniquely identify a gene e.g., AAG, ACC, AGA for genes 7, 2, and 7 , respectively. If each gene had many unique identifiers, the detection problem would be simple. For a short oligo detection system, however, there are many shared N-mers and so multiple hits must be utilized in the algorithm. The design issues are to implement a least squares estimation of the level of gene expression while introducing a pooling strategy (the $\mathbf{P}$ matrix) that minimizes the number of experiments needed.

For the synthesized data we have used $\mathrm{N}_{\mathrm{a}}=1$ and $\mathrm{N}_{\mathrm{s}}=2$. The experimental constraints result in a $\mathbf{P}$ matrix that is sparse and with repeating subunits. Denoting each pool by $\mathbf{P}_{\mathbf{i}}$, the pooling matrix is of the form:

$\left|\begin{array}{llll}\mathbf{P}_{1} & \mathbf{O} & \mathbf{O} & \mathbf{O} \\ \mathbf{O} & \mathbf{P}_{1} & \mathbf{O} & \mathbf{O} \\ \mathbf{O} & \mathbf{O} & \mathbf{P}_{1} & \mathbf{O} \\ \mathbf{O} & \mathbf{O} & \mathbf{O} & \mathbf{P}_{1} \\ \mathbf{P}_{2} & \mathbf{O} & \mathbf{O} & \mathbf{O} \\ \mathbf{O} & \mathbf{P}_{2} & \mathbf{O} & \mathbf{O} \\ & \cdots & & \\ \mathbf{O} & \mathbf{O} & \mathbf{P}_{\mathbf{p}} & \mathbf{O} \\ \mathbf{O} & \mathbf{O} & \mathbf{O} & \mathbf{P}_{\mathbf{p}}\end{array}\right|$

Each of the $\mathbf{P}_{\mathbf{i}}$ are repeated $4^{1}=4$ times because $\mathrm{N}_{\mathrm{a}}$ is 1 in our example. Each $\mathbf{P}_{\mathbf{i}}$ row vector is of length $4^{2}=16\left(\mathrm{~N}_{\mathrm{s}}\right.$ is 2$)$ and comprised of $1 \mathrm{~s}$ and $0 \mathrm{~s}$. A 1 indicates that a particular $\mathrm{N}_{\mathrm{s}^{-}}$ mer is used in the pool. $\mathbf{O}$ is a zero row vector of length $\mathrm{N}_{\mathrm{s}}$. For this example, we designed a set of $\mathrm{p}=5$ pools shown in Fig. 5 .

$\begin{array}{lccccc} & \text { P1 } & \text { P2 } & \text { P3 } & \text { P4 } & \text { P5 } \\ \text { AA } & 0 & 0 & 0 & 0 & 1 \\ \text { AC } & 1 & 0 & 0 & 0 & 0 \\ \text { AG } & 1 & 0 & 0 & 0 & 0 \\ \text { AT } & 0 & 0 & 0 & 0 & 0 \\ \text { CA } & 0 & 0 & 0 & 0 & 0 \\ \text { CC } & 0 & 0 & 1 & 0 & 0 \\ \text { CG } & 0 & 0 & 0 & 0 & 0 \\ \text { CT } & 0 & 0 & 0 & 0 & 0 \\ \text { GA } & 0 & 0 & 0 & 0 & 0 \\ \text { GC } & 0 & 0 & 0 & 0 & 0 \\ \text { GG } & 0 & 0 & 0 & 0 & 0 \\ \text { GT } & 0 & 0 & 0 & 1 & 0 \\ \text { TA } & 0 & 0 & 0 & 0 & 0 \\ \text { TC } & 0 & 0 & 0 & 0 & 1 \\ \text { TG } & 0 & 0 & 0 & 0 & 0 \\ \text { TT } & 0 & 1 & 0 & 0 & 0\end{array}$

Fig. 5. The five pools used for the synthetic genome example. PD has matrix rank 10.

Both $\mathbf{D}$ and $\mathbf{P} \mathbf{D}$ are of matrix rank 10 . Therefore the pseudoinverse exists and can be determined using singular value decomposition or other techniques. The pseudoinverse was verified using MATLAB ${ }^{\mathrm{TM}}[6]$. The calculation implements Eq. (1) and estimates

$$
\mathbf{G}_{\mathbf{L S}}=(\mathbf{P D})^{\mathrm{T}}\left(\mathbf{P D}(\mathbf{P D})^{\mathrm{T}}\right)^{-1} \mathbf{M}
$$




\section{APPLICATION TO BACTERIA}

To apply this approach to a specific bacterium like Yersinia pestis requires development of several tools and algorithms. Y. pestis is roughly a 4.3Mbase genome and has over 4,000 genes. Using an experimental system based on two 5mers $\left(\mathrm{N}_{\mathrm{a}}=\mathrm{N}_{\mathrm{s}}=5\right)$, we use the matrix approach to design a pooling strategy. The algorithm is

1. Determine the occurrence rates of every Nmer $(0,1,2$, etc. $)$

2. Starting with unique occurrences, then doublets, etc. determine which attached $\mathrm{N}_{\mathrm{a}}$ mers are contaminated by the proposed Nmer and are not already in a pool.

3 . Find the largest set of $\mathrm{N}_{\mathrm{s}}$-mers meeting criterion 2 with non-intersecting contamination sets. Place in one pool and then return to step 2 .

This approach is basically a Gram-Schmidt orthogonalization. We have calculated the D matrix for $Y$. pestis and are now designing the pooling strategy. Fig. 6 shows the percent of ORFs that have a unique $\mathrm{N}$-mer for $\mathrm{N}$ ranging from 5 to 14 . Both model and data are presented showing that a 10 -mer $(\mathrm{N}=10)$ is sufficient to transcript profile $Y$. pestis.

\section{SUMMARY}

In addition to designing the minimal pooling strategy, the matrix formulation should facilitate the design of calibration oligos and other strategies for making microarrays more quantitative and repeatable. We are also introducing design constraints in the pool specification to accommodate ribosomal and other contaminating signals.

\section{ACKNOWLEDGEMENTS}

This work was performed under the auspices of the U.S. Department of Energy by the University of California, Lawrence Livermore National Laboratory under Contract No. W7405-Eng-48. Publication UCRL-JC-141175.

The authors would also like to thank T. Slezak and the LLNL informatics team, T.

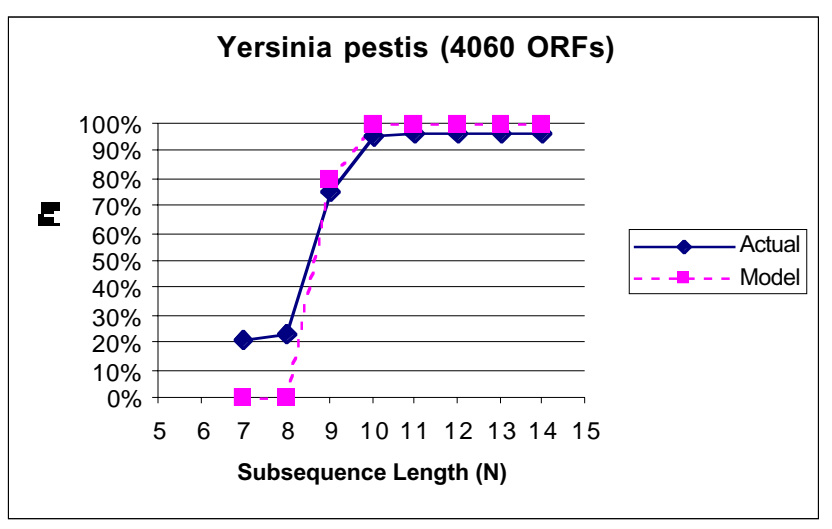

Fig. 6. Model and data overlaid showing that over $90 \%$ of the Yersinia pestis genes have at least one unique 10-mer.

Carrano (LLNL), G. Andersen and the LLNL microbiology team, and R. Drmanac (HySeq) for discussions of this R\&D.

\section{REFERENCES}

[1] Affymetrix Products: GeneChip ${ }^{\mathrm{TM}}$, [online] http://www.affymetrix.com/products/tech_pr obe.html.

[2] J. L. DeRisi, V. R. Iyer, and P. O. Brown, Exploring the metabolic and genetic control of gene expression on a genomic scale, Science, vol. 278, pp. 680-686, Oct. 1997. http://cmgm.standford.edu/pbrown/mguide/i ndex.html

[3] S. Drmanac, D. Kita, I. Labat, B. Hauser, J. Burczak, R. Drmanac, Accurate sequencing by hybridization for DNA diagnostics and individual genomics, Nature Biotechnology, 16, 54-58, 1998.

[4] J. P. Fitch, B. A. Sokhansanj, L. L. Ott, and T. R. Slezak, Informatics and simulation in a genomic approach to understanding virulence, Proc. IEEE Information Technology Applications in Biomedicine (ITAB 2000), Arlington, VA, pp. 302-307, Nov. 9-10, 2000.

[5] Universal DNA sequencing chip, [online] http://www.hyseq.com/products/puniv.html.

[6] MATLAB ${ }^{\mathrm{TM}}$ version 5.2.0, The MathWorks, Inc., January 1998. 